\title{
Disruption of the GASI gene of Pichia pastoris confers a supersecretory phenotype for Rhizopus oryzae lipase, but not for human trypsinogen
}

\author{
Hans Marx ${ }^{1}$, Michael Sauer*1,2, David Resina ${ }^{3}$, Marina Vai ${ }^{4}$, Danilo Porro ${ }^{4}$, \\ Francisco Valero ${ }^{3}$, Pau Ferrer ${ }^{3}$ and Diethard Mattanovich ${ }^{1,2}$
}

\begin{abstract}
Address: ${ }^{1}$ Institute of Applied Microbiology, BOKU - University of Natural Resources and Applied Life Sciences, Muthgasse 18, A 1190 Wien, Austria, ${ }^{2}$ School of Bioengineering, fh-campus wien - University of Applied Sciences, Muthgasse 18, A 1190 Wien, Austria, ${ }^{3}$ Department of Chemical Engineering, Universitat Autònoma de Barcelona, 08193-Bellaterra (Cerdanyola del Vallès), Spain and ${ }^{4}$ Dipartimento di Biotecnologie e Bioscienze, Università degli Studi di Milano Bicocca, P.zza della Scienza 2, 20126 Milano, Italy

* Corresponding author
\end{abstract}

from The 4th Recombinant Protein Production Meeting: a comparative view on host physiology

Barcelona, Spain. 2I-23 September 2006

Published: 10 October 2006

Microbial Cell Factories 2006, 5(Suppl I):P69 doi:I0.I I86/I475-2859-5-SI-P69

(C) 2006 Marx et al; licensee BioMed Central Ltd.

\section{Background}

The methylotrophic yeast Pichia pastoris is widely used for the heterologous production of proteins due to an advantageous secretory potential [1]. To further improve the capacity of this yeast to synthesise and secrete high levels of protein the limitations of the host have to be unravelled and overcome. Folding and disulfide bridge formation have been studied in detail and some approaches have been described to modulate these processes. However, after release from the secretory organelles like endoplasmatic reticulum and the golgi apparatus a protein still has to penetrate and cross the cell wall. This can be a major obstacle for heterologous protein secretion, but these events are less well studied up to now.

While for many heterologous proteins the cell wall is apparently not a limiting barrier, there are some indications of significant protein retention in the cell wall of S.cerevisiae $[2,3]$. In one case it was shown that deletion of the cell wall cross linking enzyme glycophospholipidanchored surface protein 1 (Gas1) leads to an almost 7 fold increase of the secreted level of human insulin like growth factor 1 in S. cerevisiae [4].

Gas1p is a glycoprotein anchored to the outer layer of the plasma membrane through a glycosylphosphatidylinositol (GPI) anchor. Gas1p shows beta-1,3-glucanosyltrans- ferase activity, required for the cell wall assembly. Disruption of GAS1 results in several morphological defects: yeast cells lose their typical ellipsoidal shape, become larger than wild type cells, are defective in bud maturation and in cell separation. The cell wall of Gas1 null mutants is highly resistant to zymolyase, more sensitive to cell wall perturbing agents such as congo red, and the cells are less protected against osmotic destabilizing agents as sodium dodecyl sulphate.

In this work we set out to clone and delete the GAS1 homologue of $P$. pastoris and to analyse the secretory capacity of the yeast cells on the basis of two proteins studied in our labs for heterologous protein production, namely human trypsinogen and Rhizopus oryzae lipase (ROL).

\section{Results}

The coding sequences of the GAS1 homologues of nine yeast species were aligned to identify regions of high homology. Within these regions PCR primers were designed to amplify a partial sequence of the P. pastoris GAS1 gene. Subsequently, it was possible to amplify the full length gene from a cDNA library. Expression of the cloned gene in S. cerevisiae fully complements the phenotype of a GAS1 deletion, indicating that the protein has the expected localization and enzymatic activity. Sequence 

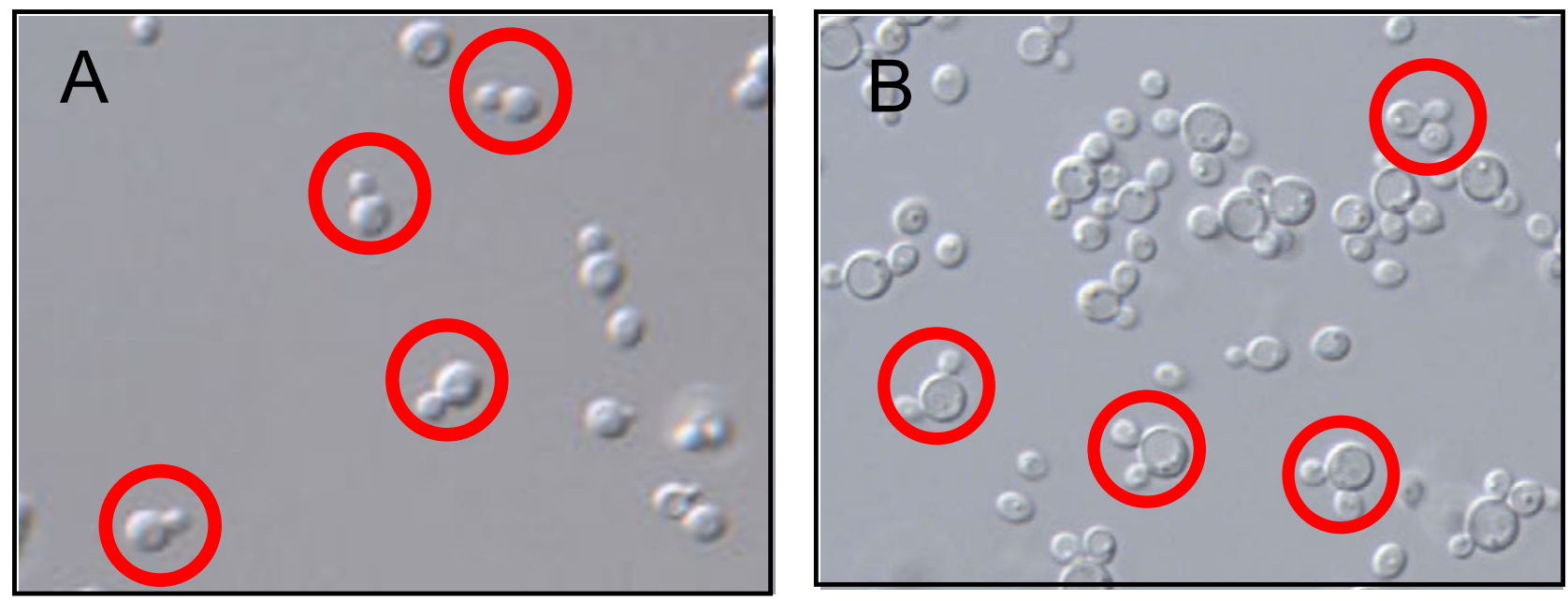

Figure I

A. P. pastoris GSII 5 wt cells showing the normal budding phenotype. B. P. pastoris GSII5 GASI::kanMX4. The GASI deleted P. pastoris strain shows frequently two buds attached to the mother cell (Mickey Mouse-like appearance) as reported for GASI deficient $S$. cerevisiae. The typical appearance is indicated by red circles.

comparison revealed the anticipated similarities with other Gas1 like proteins, such as a cysteine rich domain and a serine rich domain and a number of conserved amino acid patches within the amino terminal catalytic domain.

Targeted gene disruption of the GAS1 gene in P. pastoris was successful and led to the particular phenotype, e.g. a budding defect resulting in the accumulation of Mickey Mouse like shaped yeast aggregates (see figure 1) and sensitivity against congo red and SDS.

Finally, we tested the secretion of two model proteins (human trypsinogen and ROL) in the GAS1 deleted background in comparison to the wt $P$. pastoris strain. Secretion of human trypsinogen was not altered, while the specific secretion rate of ROL was increased approximately 2 fold.

\section{Conclusion}

As has been previously shown, different heterologous proteins encounter different bottlenecks upon expression in yeast. In any case we could show that the cell wall should not be neglected for improvement of heterologous protein secretion. We could demonstrate for the first time that the deletion of a cell wall cross linking enzyme can have a beneficial effect on secretion of a heterologous protein in P. pastoris.
Further understanding of cell wall construction and the means by which secreted proteins can cross the cell wall are therefore highly desirable

\section{References}

I. Cereghino JL, Cregg JM: Heterologous protein expression in the methylotrophic yeast Pichia pastoris. FEMS Microbiol Rev 2000, 24:45-66.

2. Rossini D, Porro D, Brambilla L, Venturini M, Ranzi BM, Vanoni M, Alberghina L: In Saccharomyces cerevisiae, protein secretion into the growth medium depends on environmental factors. Yeast 1993, 9:77-84.

3. Venturini M, Morrione A, Pisarra P, Martegani E, Vanoni M: In Saccharomyces cerevisiae a short amino acid sequence facilitates excretion in the growth medium of periplasmic proteins. Mol Microbiol 1997, 23:997-1007.

4. Vai M, Brambilla L, Orlandi I, Rota N, Ranzi BM, Alberghina L, Porro $D$ : Improved secretion of native human insulin-like growth factor I from gas I mutant Saccharomyces cerevisiae cells. Appl Environ Microbiol 2000, 66:5477-5479.

Publish with Bio Med Central and every scientist can read your work free of charge

"BioMed Central will be the most significant development for disseminating the results of biomedical research in our lifetime. "

Sir Paul Nurse, Cancer Research UK

Your research papers will be:

- available free of charge to the entire biomedical community

- peer reviewed and published immediately upon acceptance

- cited in PubMed and archived on PubMed Central

- yours - you keep the copyright
BioMedcentral 